\title{
Metagonimoides oregonensis (Heterophyidae: Digenea) Infection In Pleurocerid Snails and Desmognathus quadramaculatus Salamander Larvae In Southern Appalachian Streams
}

\author{
Author(s): Lisa K. Belden, William E. Peterman, Stephen A. Smith, Lauren R. Brooks , E. F. Benfield, \\ Wesley P. Black, Zhaomin Yang, and Jeremy M. Wojdak \\ Source: Journal of Parasitology, 98(4):760-767. 2012. \\ Published By: American Society of Parasitologists \\ DOI: http://dx.doi.org/10.1645/GE-2986.1 \\ URL: http://www.bioone.org/doi/full/10.1645/GE-2986.1
}

BioOne (www.bioone.org) is a nonprofit, online aggregation of core research in the biological, ecological, and environmental sciences. BioOne provides a sustainable online platform for over 170 journals and books published by nonprofit societies, associations, museums, institutions, and presses.

Your use of this PDF, the BioOne Web site, and all posted and associated content indicates your acceptance of BioOne's Terms of Use, available at www.bioone.org/page/terms of use.

Usage of BioOne content is strictly limited to personal, educational, and non-commercial use. Commercial inquiries or rights and permissions requests should be directed to the individual publisher as copyright holder. 


\title{
METAGONIMOIDES OREGONENSIS (HETEROPHYIDAE: DIGENEA) INFECTION IN PLEUROCERID SNAILS AND DESMOGNATHUS QUADRAMACULATUS SALAMANDER LARVAE IN SOUTHERN APPALACHIAN STREAMS
}

\author{
Lisa K. Belden, William E. Peterman*, Stephen A. Smith†, Lauren R. Brooks, E. F. Benfield, Wesley P. Black, Zhaomin \\ Yang, and Jeremy M. Wojdakł \\ Department of Biological Sciences, Virginia Tech, Blacksburg, Virginia 24061. e-mail: belden@vt.edu
}

\begin{abstract}
Metagonimoides oregonensis (Heterophyidae) is a little-known digenetic trematode that uses raccoons and possibly mink as definitive hosts, and stream snails and amphibians as intermediate hosts. Some variation in the life cycle and adult morphology in western and eastern populations has been previously noted. In the southern Appalachians, Pleurocera snails and stream salamanders, e.g., Desmognathus spp., are used as intermediate hosts in the life cycle. We completed a series of studies in this system examining some aspects of larval trematode morphology and first and second intermediate host use. Molecular sequencing of the 28S rDNA of cercariae in our survey placed them clearly within the heterophyid family. However, light and scanning electron microscopy revealed both lateral and dorso-ventral finfolds on the cercariae in our region, whereas original descriptions of $M$. oregonensis cercariae from the west coast indicate only a dorso-ventral finfold, so further work on the systematics of this group may be warranted. A survey of first intermediate host, Pleurocera proxima, from 7 streams in the region identified only M. oregonensis, virgulate-type cercariae, and cotylomicrocercous-type cercariae in the streams, with $M$. oregonensis having the highest prevalence, and the only type present that use amphibians as second intermediate hosts. Based on clearing and staining of 6 Desmognathus quadramaculatus salamander larvae, we found that individual salamanders could have over 600 metacercariae, which form between muscle fibers throughout the body. Histological observations suggest that the metacercariae do not cause excessive tissue damage or inflammation, and likely persist through metamorphosis, thereby transmitting potentially large numbers of worms to definitive host raccoons foraging along streams.
\end{abstract}

Amphibians serve as either intermediate or definitive hosts for hundreds of species of digenetic trematodes (Smyth and Smyth, 1980; Prudhoe and Bray, 1982). Most studies examining trematodes in amphibians have been parasite surveys, establishing intensity and prevalence of infection of various parasites in amphibian hosts (Najarian, 1955; Goater et al., 1987; McAlpine and Burt, 1998). More recently, surveys have been expanded to examine the influence of landscape level variables in determining parasite community structure within amphibian populations (Koprivnikar et al., 2006; Schotthoefer et al., 2011). A few additional studies have described parasite life cycles of species using amphibians as definitive hosts and have begun investigating hostparasite interactions (Joy and Pennington, 1998; Zelmer and Esch, 2000; Bolek and Janovy, 2008; Bolek et al., 2010).

Some trematode species that use amphibians as intermediate hosts have also become the focus of more intensive study in recent years. For example, significant mortality and dramatic limb malformations can be associated with Ribeiroia ondatrae infection in larvae of some amphibian species (Johnson et al., 1999, 2002). Echinostomes are another group that has received increased attention in recent years. Numerous species within this family, e.g., Echinostoma trivolvis, Echinostoma revolutum, and Echinoparyphium spp., use larval amphibians as second intermediate hosts and can alter tadpole kidney function, and sometimes cause edema, especially in young tadpoles (Schotthoefer et al., 2003; Holland et al., 2007). Studies of both $R$. ondatrae and echinostomes are appearing more frequently in the ecological literature, in part because they have proved to be useful systems for elucidating general ecological processes underlying disease

Received 21 September 2011; revised 27 February 2012; accepted 6 March 2012

* Division of Biological Sciences, University of Missouri, Columbia, Missouri 65211.

$\uparrow$ Department of Biomedical Sciences and Pathobiology, VirginiaMaryland Regional College of Veterinary Medicine, Blacksburg, Virginia 24061

tDepartment of Biology, Radford University, Radford, Virginia 24142.

DOI: 10.1645/GE-2986.1 dynamics in natural systems (Johnson et al., 2008; Szuroczki and Richardson, 2009; Belden and Wojdak, 2011). However, for most of the trematode species that infect amphibians, little remains known beyond basic infection information.

Metagonimoides oregonensis was first described from adult parasites collected from the small intestine of a raccoon in Oregon (Price, 1931). Soon after, definitive host surveys established the presence of this trematode across much of the United States, from North Carolina to Oregon, and subsequently the life cycle was experimentally determined in the laboratory (Burns and Pratt, 1953). Raccoons, and possibly mink, appear to be the primary definitive hosts, with adult parasites found in the small intestine. Eggs are passed in the feces, and miracidia infect stream-dwelling prosobranch snails, which serve as the first intermediate host. It remains unknown whether the miracidia are free-swimming or must be consumed by the first intermediate host snails (Burns and Pratt, 1953). In the western United States, the first intermediate host are Juga spp. (=Oxytrema =Goniobasis), while in the eastern United States the first intermediate host are Pleurocera spp. (=Goniobasis, Dillon, 2011). Cercariae develop within rediae in the snails; there is no sporocyst stage. In Oregon, multiple variations of the life cycle have been reported. Metagonimoides using Juga (=Oxytrema) silicula either form metacercariae within the snails or produce free-swimming cercariae that then form metacercariae in Rana spp. frogs (Burns and Pratt, 1953). The latter authors experimentally confirmed that cercariae could penetrate red-legged frogs, Rana aurora, which was suggested to be a common natural host for the parasite, as well as leopard frogs, Rana pipiens, and bullfrogs, Lithobates catesbeianus (=Rana catesbeiana). However, Metagonimoides using Juga (=Oxytrema) nigrina appear to lack a free-swimming stage and form metacercariae only within the first intermediate snail host (Ingles, 1935). In North Carolina, Lang and Gleason (1967) suggested that there were no metacercariae formed within the snails hosts; all rediae produced free-swimming cercariae that leave the snail and infect larval stream salamanders, especially Desmognathus quadramaculatus, black-bellied salamanders. Lang et al. (1968) followed up these studies on life cycle variation by examining adult parasites 
collected from raccoons in Oregon and North Carolina. They suggested that there were "significant differences in morphology" and that $M$. oregonensis from these different sites should be considered "separate strains of the same species." A complex of cryptic Metagonimoides species may exist, so we caution that our usage of "Metagonimoides oregonensis" throughout the manuscript is based on current knowledge, and nomenclature may change with future studies. Since the study of Lang et al. (1968), little work beyond the mention of $M$. oregonensis in host surveys (e.g., Goater et al., 1987) has been done on this parasite system.

The goal of the present study was to begin to explore the hostparasite interactions in this system, with a focus on first intermediate host Pleurocera proxima snails, and a commonly noted second intermediate host salamander, D. quadramaculatus. This salamander species is highly aquatic, spending more time in the streams than most of the other Desmognathus spp. salamanders in the eastern United States. They are, therefore, likely to be commonly exposed to trematode cercariae emerging from streamdwelling snails. In addition, they occur at exceptionally high density in Appalachian headwater streams, with adults and juveniles reported at a density of greater than 1.1 per $\mathrm{m}^{2}$ and larvae reported at densities up to 29 per $\mathrm{m}^{2}$ (Peterman et al., 2008; Milanovich, 2010). These high densities might allow efficient parasite transmission to the definitive hosts. We sequenced the $28 \mathrm{~S}$ rDNA of $M$. oregonensis cercariae and used light and scanning electron microscopy to characterize the morphology of M. oregonensis larval forms. We also surveyed first intermediate host $P$. proxima snails and second intermediate host $D$. quadramaculatus larvae to estimate infection prevalence, examined the possible correlation between visible metacercariae and total metacercariae within larval salamanders, and completed histological observations to examine the distribution of cysts within the salamanders and the potential host response to infection.

\section{MATERIALS AND METHODS}

Initially, snails and salamanders for this study were collected from an un-named headwater stream in the Little Tennessee River Basin in the Nantahala National Forest, Macon County, North Carolina (hereafter referred to as the primary study site). Pleurocera (=Goniobasis) proxima were first collected from the site in January $(\mathrm{n}=52)$ and April $(\mathrm{n}=98)$, 2007. Snails were returned to the laboratory and placed in individual 120$\mathrm{ml}$ cups filled with dechloraminated tap water at room temperature for 3 $4 \mathrm{hr}$, and then screened for free-swimming cercariae (patent infections) using a stereomicroscope. Emerging cercariae were removed from the cups with a pipette, placed on slides, and viewed and photographed using both brightfield viewing, following staining with neutral red, and darkfield viewing with no staining. Initial identifications were done using Schell (1985) and, for the most abundant cercariae that were being shed, which were tentatively identified as $M$. oregonensis, they were also compared with the description of Burns and Pratt (1953). Several cercariae samples from individual snails were preserved in $95 \%$ ethanol and stored at $-20 \mathrm{C}$ for subsequent molecular sequencing.

To provide further evidence for the tentative morphological identification of $M$. oregonensis, molecular sequencing of the ls rDNA of cercariae was performed using a modified set of procedures from Olson et al. (2003). A sample of $\sim 10$ cercariae from a single snail obtained from the initial North Carolina site was used for sequencing. Immediately prior to DNA extraction, the sample was rinsed 3 times in Buffer TE, and total DNA was extracted using the QIAamp DNA Micro Kit (Qiagen, Germantown, Maryland), following the manufacturer's instructions. The ls rDNA was amplified via PCR using Ready-To-Go PCR beads (GE Healthcare, Piscataway, New Jersey) according to the manufacturer's instructions using the primers (LSU5 and 1500R) and cycling parameters from Olson et al. (2003). The resulting PCR product with an expected size of approximately 1,400 base pairs was blunt ended using T4 DNA polymerase (New England Biolabs, Ipswich, Massachusetts) and gel extracted using the QIAquick Gel Extraction Kit (Qiagen, Germantown, Maryland). The PCR product was ligated into the EcoRV site in pZErO-2 (Life Technologies, Carlsbad, California) using the Quick Ligation Kit (New England Biolabs, Ipswich, Massachusetts) and transformed into DH5 $\alpha$-MCR (Life Technologies, Carlsbad, California). Plasmids with the correct size insert were identified by colony PCR screening of the transformants. Correct transformants were subsequently used for plasmid isolation using the QIAprep Spin Miniprep Kit (Qiagen). The isolated plasmid was subjected to DNA sequencing using the BigDye Terminator v3.1 Cycle Sequencing Kit (Life Technologies, Carlsbad, California) and the universal M13F and M13R vector priming sites. Sequence acquisition was performed by the Genome Sequencing and Analysis Core Resource (Duke University, Durham, North Carolina), and chromatograms were analyzed with Chromas (Technelysium, Brisbane, Queensland, Australia). We completed a BLAST search to determine sequence similarity of the resulting 1,381 bp sequence, which was deposited in GenBank under the accession number JQ995473.

We placed our sequence within a phylogenetic framework of published Heterophyidae sequences. Representative sequences from the $28 \mathrm{~S}$ region of heterophyids were accessed on GenBank, and Rugogaster hydrolagi (Rugogastridae) and Heronimus mollis (Heronimidae) were selected as outgroups for the analysis (Olson et al., 2003). Sequences were aligned in MEGA5 (Tamura et al., 2011) using Clustal W (Larkin et al., 2007). We used the web-based program FindModel (Los Alamos National Laboratory, 2010) to identify our most likely nucleotide substitution model. We then constructed maximum likelihood and Bayesian trees using MEGA5 and MrBayes 3.1.2, respectively (Huelsenbeck and Ronquist, 2001; Tamura et al., 2011). For the likelihood analysis we used 10,000 bootstrap replicates to estimate node support for trees constructed using the general time reversible (GTR) model with gamma-distributed mutation rates. Bayesian trees were constructed using the same GTR evolutionary model with gamma-distributed rate variation. Analysis consisted of 2 concurrent runs with 4 simultaneous chains for $5 \times 10^{6}$ generations with a sample frequency of 1,000 . Convergence of the topology was assumed when the split standard deviation between runs was $<0.01$.

To provide additional detail on the morphology of $M$. oregonensis larval forms in the region, we examined additional cercariae and rediae in 2011 using scanning electron microscopy. We collected rediae and cercariae from infected $P$. proxima snails that were identified morphologically as $M$. oregonensis using the same light microscopy procedures outlined above. These samples were collected in southwest Virginia, approximately $250 \mathrm{~km}$ northeast of the site in North Carolina; cercariae were morphologically identical to the North Carolina samples. After dissecting the snails and removing the trematode larvae (cercariae and rediae), they were submerged in $3 \%$ glutaraldehyde/3\% formaldehyde in $0.1 \mathrm{M}$ sodium cacodylate buffer at $\mathrm{pH} 7.4$ for $>1 \mathrm{hr}$. Tissues were then rinsed in water for $5 \mathrm{~min}$, submerged in $2 \% \mathrm{OsO}_{4}$ for $5 \mathrm{~min}$, rinsed again in water for $5 \mathrm{~min}$, then processed through a series of increasing concentrations of ethanol $(25,50,75,85,95,100,100 \%)$ for 5 min each. Tissues were dried by submerging them in hexamethyldisilazane and allowed to air dry, then sputter coated with gold. Electron micrographs were taken with a JEOL Neoscope environmental SEM at $10 \mathrm{kv}$.

A snail survey of an additional 6 streams in the Little Tennessee River Basin in North Carolina was completed in summer 2009 to obtain a broader spatial perspective of $M$. oregonensis prevalence in first intermediate host snails, $P$. proxima. At each site, between 26 and 53 snails were haphazardly collected. These were dissected in the laboratory, and larval trematodes were identified morphologically as either $M$. oregonensis, virgulate-type cercariae, or cotylomicrocercous-type cercariae (Schell, 1985). Of these types, only $M$. oregonensis use amphibians as second intermediate hosts. Goater et al. (1987) surveyed over 350 Desmognathus spp. salamanders in western North Carolina and described 2 larval trematodes encysting in them, with $M$. oregonensis being the only species encysting in the muscle fibers.

In North Carolina, D. quadramaculatus can have up to a 4-yr larval period, with hatchlings emerging from eggs during the summer at a size of approximately 11-16 mm SVL (snout-vent length) and metamorphosis into a juvenile stage occurring when individuals are approximately 35 $45 \mathrm{~mm}$ SVL (Petranka, 1998). We examined $M$. oregonensis infection intensity in 6 D. quadramaculatus larvae (SVL range 13-26 mm) collected 

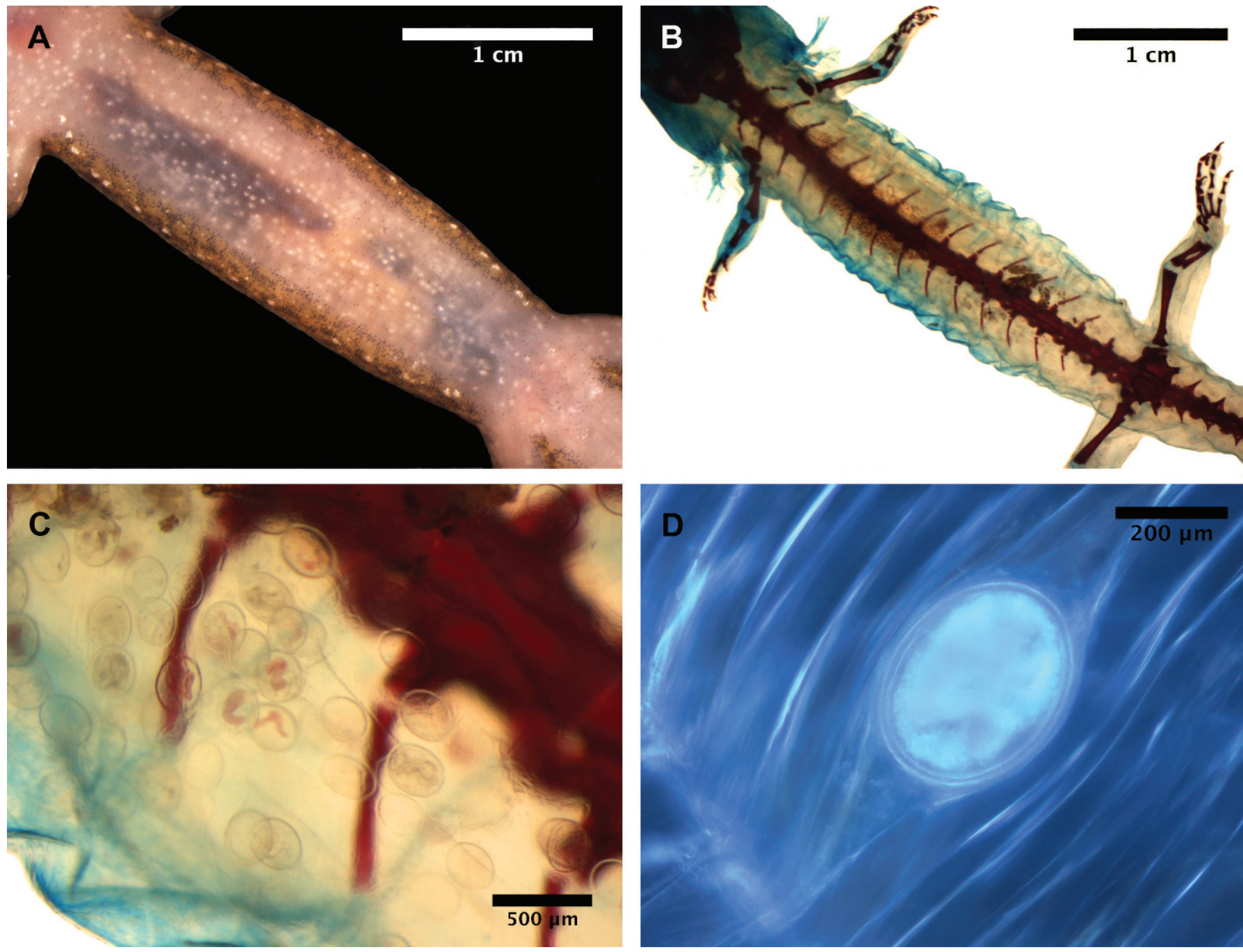

Figure 1. Metacercariae from Desmognathus quadramaculatus. (A) Cysts visible on ventral surface of salamander larva. (B) Same salamander following clearing and staining. (C) Close-up of metacercariae following clearing and staining. (D) Individual metacercaria embedded between muscle fibers.

in 2008 from the primary field site described above by counting the number of visible metacercariae cysts on the ventral surface between both sets of limbs (Fig. 1A) and then comparing visible cyst number with total infection of the same body region enumerated after clearing and staining (Fig. 1B, C). The clearing and staining protocol, which results in blue cartilage and red bones in transparent soft tissue, was modified from Hanken and Wassersug (1981). After killing salamanders in buffered MS222, specimens were fixed in $10 \%$ neutral buffered formalin for at least $24 \mathrm{hr}$ and then rinsed in tap water several times before being post-fixed and stored in $70 \%$ ethanol until processing. For staining, specimens were placed in a solution of alcian blue cartilage stain for $24 \mathrm{hr}(20 \mathrm{mg}$ alcian blue in a solution of $70 \mathrm{ml}$ 100\% ethanol:30 ml glacial acetic acid). They were then transferred to a solution of $70 \mathrm{ml} 100 \%$ ethanol:30 ml glacial acetic acid for $1 \mathrm{hr}$, then to $100 \%$ ethanol for $24 \mathrm{hr}$. Specimens were then soaked overnight in tap water. They were then transferred to a solution of $1 \%$ trypsin in $30 \%$ saturated sodium borate (note: saturated sodium borate is approximately $4 \mathrm{~g}$ in $100 \mathrm{ml}$ ). After $24 \mathrm{hr}$, if cartilage could be seen, they were then transferred to a solution of $0.5 \% \mathrm{KOH}$ with enough alizarin red-S added to make a dark purple solution. If cartilage could not be seen, they were left in the trypsin solution for additional time until cartilage was visible. After $24 \mathrm{hr}$ in the alizarin red-S solution, samples were transferred to a $0.5 \% \mathrm{KOH}$ solution that was changed twice over the subsequent $24 \mathrm{hr}$. Specimens were then moved through a graded series of $0.5 \% \mathrm{KOH}$ :glycerin at $2: 1,1: 1,1: 2$, and finally to $100 \%$ glycerin, as the specimens cleared at each step. Following the clearing and staining procedure, we counted all metacercariae visible from the ventral side of the animal between both sets of limbs (same region that was counted prior to clearing and staining).

Microscopy suggested the presence of the metacercariae in between the muscle fibers (Fig. 1D), as had been suggested by Goater et al. (1987). To examine the distribution and possible pathology associated with the cysts in more detail, an additional salamander larva (32 $\mathrm{mm} \mathrm{SVL}$ ) was used for histological analysis following fixation in $10 \%$ neutral buffered formalin. After fixation, the salamander was sliced into $2-3 \mathrm{~mm}$ sections and placed in cassettes for processing by standard techniques. Briefly, tissues were dehydrated through an increasing ethanol series, cleared in xylene, infiltrated and embedded in paraffin, sectioned at 3-4 $\mu \mathrm{m}$, and stained with hematoxylin and eosin (H\&E).

\section{RESULTS}

Previous descriptions of the cercariae (Ingles, 1935; Burns and Pratt, 1953) refer to a tail emerging from a deep socket, with a dorso-ventral finfold starting half-way down the tail and continuing down to the tip (pleurolophocercous type). Our SEM images show the deep socket and dorso-ventral finfold, 
but also a lateral finfold starting at the tail's base that diminishes around the tail's midpoint (Fig. 2A-D; also see image of parapleurolophocercous cercaria in Schell, 1985). Burns and Pratt (1953) described cercariae with bodies in the extended position measuring 45 by $240 \mu \mathrm{m}$, while ours measured approximately $40-80 \mu \mathrm{m}$ wide by $80-195 \mu \mathrm{m}$ long; exact size comparisons are difficult because the body dimensions vary greatly based on the state of contraction. Conspicuous eyespots were present $68 \mu \mathrm{m}$ back from the anterior terminus of the body, as in previous descriptions (66 $\mu \mathrm{m}$ in Burns and Pratt 1953). Morphology of the rediae was largely consistent with the prior descriptions of $M$. oregonensis (Ingles, 1935; Burns and Pratt, 1953), ours being $\sim 200 \mu \mathrm{m}$ wide, $\sim 730 \mu \mathrm{m}$ long, and sausageshaped (Fig. 2E, F).

The 28s rDNA sequence also was consistent with expectations for $M$. oregonensis; based on the BLAST search, the presumptive $M$. oregonensis sequence was most similar (94\%) to a sequence of Cryptocotyle lingua, another heterophyid species. We did not attempt a complete phylogenetic analysis of all heterophyids, but our assessment does demonstrate the placement of our sequence within the Heterophyidae (Fig. 3).

In January 2007, 4 of 52 snails (7\%) from our primary study site were shedding $M$. oregonensis cercariae (no other trematode species were seen) and in April, 24 of 98 (24\%) were shedding $M$. oregonensis cercariae and 2 were shedding virgulate-type cercariae. Metagonimoides oregonensis-infected snails were also present at 5 of the additional 6 sites we surveyed in 2009 in the Little Tennessee River Basin, with a prevalence ranging from 6 to $20 \%$. Other morphotypes of cercariae identified at these 6 sites were virgulate-type cercariae (prevalence $0-4 \%$ ) and cotylomicrocercous type (prevalence 0-6\%). Two snails were co-infected with $M$. oregonensis and virgulate-type cercariae at 1 of the sites. All 6 salamanders we examined contained metacercariae, with between 53 and 687 total cysts present in the body region we examined. A strong correlation was found between visible and total metacercariae in the 6 salamanders $\left(r^{2}=0.99 ; P<0.0001\right.$; regression equation, total cysts $=-9.08+10.37$ [visible cysts]).

Histological examination of salamander tissues confirmed that cysts were randomly distributed in the musculature and subcutaneous tissues of the head, body, and tail of the salamander (Fig. 4A). Cysts were also observed in the limbs with clearing and staining procedures, but no limbs were sectioned for histology. The cysts were clearly identifiable as trematode metacercariae, since the body of sectioned larva was filled with parenchyma without a body cavity and surrounded by a homogenous fibrous cell wall. The cyst surrounding the trematode consisted of several eosinophilic, lamellar layers of host tissue and was not associated with any apparent inflammatory response (Fig. 4B). In addition, several larval trematodes were encysted within the globe of the eye, and at least 1 was observed free in the coelomic cavity of the salamander. It is not clear whether the cysts in the eyes were additional $M$. oregonensis metacercariae, although the morphology and size was consistent with the $M$. oregonensis metacercariae in other regions of the body. The trematode in the body cavity is more of a mystery because we have not observed any other trematodes in the pleurocerid snails in this region that infect amphibians. This could be another $M$. oregonensis specimen in an aberrant location or it could be on its way to forming a cyst in the musculature.
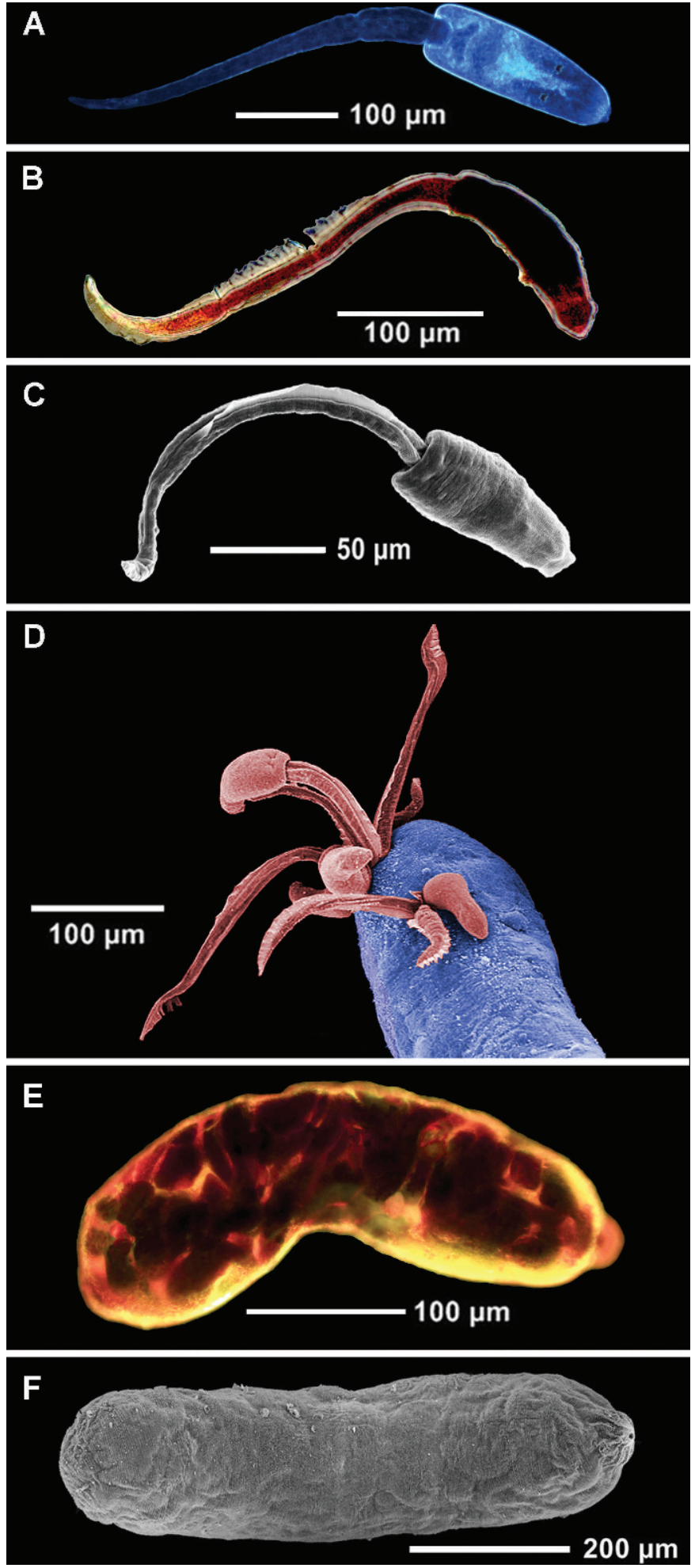

FIGURE 2. Micrographs of Metagonimoides oregonensis larvae. (A) Darkfield light microscope image of cercariae. (B) Darkfield image of cercaria stained with Lugol's solution. (C) SEM image of cercaria showing lateral finfold extending from base of tail. (D) Colorized SEM image of cercariae emerging from a redia. Note presence of both dorso-ventral and lateral finfolds on cercariae. (E) Darkfield image of redia stained with Lugol's solution, showing many cercariae inside. (F) SEM image of redia. 


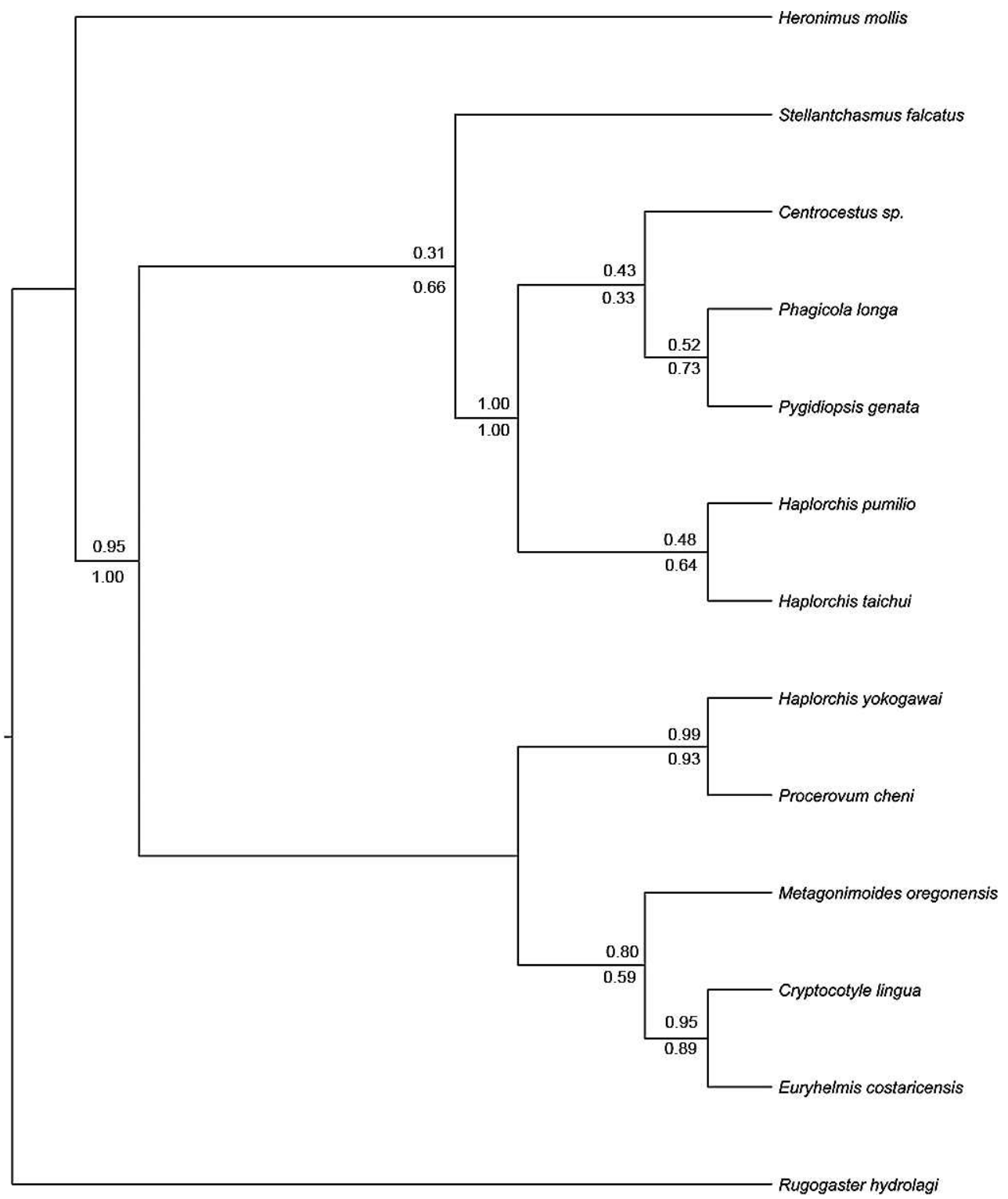

FIGURE 3. Phylogenetic tree showing relationships of select species of Heterophyidae. Maximum likelihood bootstrap support values are given above the line, and Bayesian posterior probabilities are given below the line at each node.

\section{DISCUSSION}

Variation in the morphology of adult $M$. oregonensis from Oregon and North Carolina has been previously noted (Lang et al., 1968). Here, we found initial evidence that cercariae morphology might also differ among populations. Original descriptions of cercariae from Oregon (Burns and Pratt, 1953) and California (Ingles, 1935) describe a pleurolophocercous cercariae with a single dorso-ventral finfold, while our images and description suggest the cercariae is of the parapleurolophocercous type, with 2 finfolds (dorso-ventral and lateral). Schell (1985) reports that both types can be produced by heterophyid trematodes. Our sequence results also confirmed these cercariae as heterophyids. The only heterophyids that have been identified as emerging from Pleurocera snails in streams in this region are M. oregonensis (Lang and Gleason, 1967; Lang, 1968). Indeed, Lang and Gleason (1967) state that "a cercaria identical to that described for $M$. oregonensis by Burns and Pratt was found to emerge from the snail Goniobasis proxima collected from streams near Chapel Hill." The only other heterophyids in North America that commonly use amphibians as second intermediate hosts are species of Euryhelmis (Prudhoe and Bray, 1982; Sutherland, 2005). These heterophyids, which appear to be most abundant in the Pacific Northwest, use hydrobiid snails as first intermediate hosts (there are no hydrobiids in the streams we have surveyed) and produce cercariae that lack eyespots (Senger and Macy, 1952; Anderson and Pratt, 1965). In our stream survey, we identified virgulate-type and cotylomicrocercous-type cercariae in addition to $M$. oregonensis cercariae, but typically these other types were at lower prevalence. Trematode families producing cotylomicrocercous-type cercariae include Opecoelidae, which use aquatic invertebrates and fish as second intermediate hosts, while families producing virgulate-type cercariae include Lecithodendriidae and Allassogonoporidae, which use aquatic invertebrates as second 

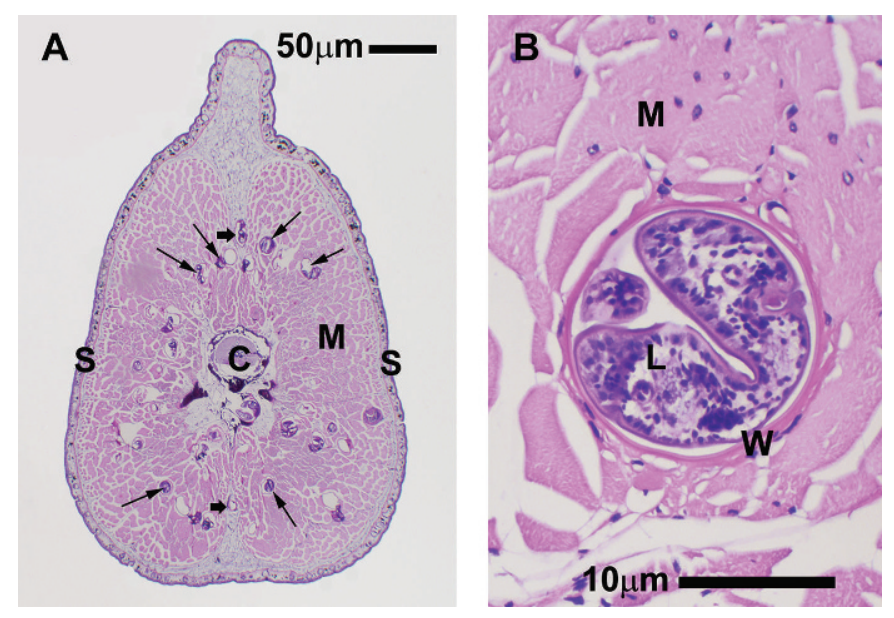

Figure 4. Histological images. (A) Cross-section from the posterior end of the tail of a salamander larva showing approximately 25 cysts, each containing a single metacercaria. The majority of the metacercariae are within the muscle tissue (arrows), but a few can also be seen in the subcutaneous tissues (fat arrows) of this salamander. Magnification $\times 20$, H\&E stain. (B) Larval trematode within cyst in musculature of salamander. Note the centrally located larval trematode that is circumscribed by an eosinophilic layer of host cells. Magnification $\times 400, \mathrm{H} \& \mathrm{E}$ stain $(\mathrm{S}=$ skin, $\mathrm{M}=$ muscle, $\mathrm{C}=$ spinal cord, $\mathrm{L}=$ larval trematode, $\mathrm{W}=$ host cell wall).

intermediate hosts. No cercariae other than M. oregonensis that form metacercariae in muscle tissue of amphibians have been identified in our surveys.

Our stream survey indicated that $M$. oregonensis is present in many of the streams in this region of North Carolina (6 of the 7 streams surveyed had infected snails) and can have prevalences in the snail hosts up to $20 \%$. Lang (1968) described the prevalence of M. oregonensis as ranging from 14.4 to $52.7 \%$ over the course of $3 \mathrm{yr}$ in a North Carolina stream in the same region. Thus, $M$. oregonensis may be a commonly encountered parasite for these salamanders in the broader geographic region. Metagonimoides oregonensis from North Carolina can infect a wide array of amphibians in laboratory trials, including Desmognathus spp. salamanders, as well as Rana clamitans, Acris spp., Pseudacris spp., and Bufo fowleri (Lang and Gleason, 1967). No details were provided in that study regarding the number of cercariae or number of metacercariae formed. In Oregon, $M$. oregonensis have been reported to encyst in at least 3 species of ranid frogs in the laboratory, although, again, no details of these exposures are provided (Burns and Pratt, 1953). Variation in host susceptibility to $M$. oregonensis and the likelihood of transmission to the definitive hosts remains to be determined. However, in our region in the southern Appalachians, stream salamanders are much more likely hosts, since anurans very rarely breed in these streams.

We found a strong relationship between visible metacercariae and total metacercariae within the region of the body we examined. Approximately $10 \%$ of the total cysts were visible on the ventral surface of the larval salamanders. Histology suggested that metacercariae were randomly distributed throughout the muscle tissues in the body, so this correlation is not surprising. This pattern, if general and robust, might allow mark-recapture studies that follow infection intensity of individual salamanders through time, which is impossible with many parasite species. However, this correlation would likely be limited to relatively small larvae. Pigmentation increases on the ventral surface of $D$. quadramaculatus as they age, which should make distinguishing visible cysts much more difficult.

Goater et al. (1987) surveyed parasites in 397 Desmongthaus salamanders of 4 species (Desmongthaus marmoratus (=Leurognathus marmorata), D. quadramaculatus, Desmongthaus monticola, and Desmongthaus ochrophaeus) in several streams in Macon County, North Carolina, not far from our study site. They recorded 10 species of adult helminth parasites (mostly nematodes) from the salamanders, although infection intensities were low for all of the species. They also recorded 5 species of larval helminths, including $M$. oregonensis, which they noted as abundant in both D. quadramaculatus and D. marmoratus, the 2 species that spend the most time in streams, although neither prevalence nor intensity of infection was quantified.

Our infection estimates ranged up to 687 cysts in a single individual salamander, but this is an underestimate of total cyst burden because we focused solely on the body between the fore and hind limbs. Cysts were also located in the head, limbs, and tail, but visible cysts are harder to consistently locate and count in these regions. Regardless, it is clear that these salamanders are accumulating large numbers of cysts over the course of their larval period and that there is little pathology associated with infection, so that many cysts are likely retained throughout the life of the salamander. The fitness consequences of these metacercariae on their salamander hosts is not known, but it is clear that raccoons feeding on these stream salamanders could potentially be continually exposed to large numbers of metacercariae. Adult worm burdens can indeed be high, such as the over 2,300 adults reported in a raccoon from Georgia (Schaffer et al., 1961), although $M$. oregonensis prevalence in raccoon populations in the southeast is typically below 20\% (Schaffer et al., 1961; Bafundo et al., 1980).

Setting up the life cycle of $M$. oregonensis in the laboratory for further investigation may be feasible, but it will require a good surrogate definitive host. Burns and Pratt (1953) reported minimal success using golden hamsters as proxy definitive hosts for $M$. oregonensis in the laboratory. They obtained only a single adult worm 1 wk after feeding the hamster 20 metacercariae from a snail, and only 50-60 adults were obtained after feeding approximately 1,000 metacercariae from a snail. They did not have any more success when using cysts from $R$. aurora. From 50 cysts that had been in the frogs for 70 days, only 4 adult worms were recovered in the hamsters. From 12 cysts that were 44 days old, no adult worms were recovered. They suggest, based on cyst morphology, that the metacercariae in the frogs require about 45 days to mature and become infective. However, Lang and Gleason (1967) fed 70 metacercariae that had been in B. fowleri tadpoles for only 30 days to 2 hamsters and recovered a total of 52 adult worms after 10 days. Thus, a common laboratory model may hold promise as a surrogate definitive host, but more quantitative testing, perhaps with additional species like rats and mice, is warranted.

Studies examining the dynamics and importance of larval trematodes in aquatic systems are becoming increasingly common (Kuris et al., 2008; Lafferty et al., 2008; Kaplan et al., 2009). While much of this work has occurred in marine systems, larval trematodes in freshwater systems might also mediate important energy fluxes across terrestrial-aquatic boundaries, constitute an important part of the zooplankton community, and influence host 
population dynamics. Based on our surveys and prior work (Goater et al., 1987; Goater, 1990), M. oregonensis appears to be a common parasite in stream systems in the Southern Appalachians that could potentially have important broader impacts in these systems. However, as this work moves forward, proper species identification is critical, since different parasite species may have different transmission dynamics, use hosts differently, and ultimately have varying impacts in these systems.

Species identification has traditionally been very difficult for larval trematodes, since taxonomy is based on adults, which tend to have a broader suite of useful morphological characters. Molecular identification, such as we have used, and species "barcoding" are allowing the study of these larval forms in more detail (Locke et al., 2011), and more advanced microscopy, especially SEM, might be a powerful tool for observing additional morphological detail of larval forms. Care must be taken though, since several recent studies have demonstrated the presence of numerous cryptic species within common North American trematode families (Detwiler et al., 2010; Locke et al., 2010). Given the prior variation in life history reported across the range and the morphological differences that have been identified in adult $M$. oregonensis (Lang et al., 1968), and given our suggestion that variation in cercariae morphology seems to be present, the presence of multiple species within the $M$. oregonensis group remains a possibility that needs further exploration.

\section{ACKNOWLEDGMENTS}

This research was supported by the Virginia Tech Advance program, which was supported by National Science Foundation Grant SBE0244916, as well as by National Science Foundation grants DEB-0918960 (L. Belden) and DEB-0918656 (J. Wojdak). A Radford University College of Science and Technology Faculty Research grant provided funding for the SEM work. We thank Skylar Hopkins for her invaluable assistance with the electron microscopy.

\section{LITERATURE CITED}

Anderson, G. A., And I. Pratt. 1965. Cercaria and first intermediate host of Euryhelmis squamula. Journal of Parasitology 51: 13-15.

Bafundo, K. W., W. E. Wilhelm, And M. L. Kennedy. 1980. Geographic variation in helminth parasites from the digestive tract of Tennesee raccoons, Procyon lotor. Journal of Parasitology 66: 134-139.

Belden, L. K., AND J. M. WoJdak. 2011. The combined influence of trematode parasites and predatory salamanders on wood frog (Rana sylvatica) tadpoles. Oecologia 166: 1077-1086.

BoleK, M. G., AND J. JANOVY, JR. 2008. Alternative life cycle strategies of Megalodiscus temperatus in tadpoles and metamorphosed anurans. Parasite 15: 396-401.

- H. R. Tracy, and J. JANOVy, JR. 2010. The role of damselflies (Odonata: Zygoptera) as paratenic hosts in the transmission of Halipegus eccentricus (Digenea: Hemiuridae) to anurans. Journal of Parasitology 96: 724-735.

Burns, W. C., and I. Pratt. 1953. The life cycle of Metagonimoides oregonensis Price (Trematoda: Heterophyidae). Journal of Parasitology 39: 60-69.

Detwiler, J. T., D. H. Bos, And D. J. Minchella. 2010. Revealing the secret lives of cryptic species: Examining the phylogenetic relationships of echinostome parasites in North America. Molecular Phylogenetics and Evolution 55: 611-620.

Dillon JR, R. T. 2011. Robust shell phenotype is a local response to stream size in the genus Pleurocera (Rafinesque, 1918). Malacologia 53: $265-277$.

GoAter, T. M. 1990. Helminth parasites indicate predator-prey relationships in desmognathine salamanders. Herpetological Review 21: 32 33.

, G. W. Esch, AND A. O. Bush. 1987. Helminth parasites of sympatric salamanders: Ecological concepts at infracommunity, component and compound community levels. The American Midland Naturalist 118: 289-300.

Hanken, J., and R. Wassersug. 1981. The visible skeleton. Functional Photography 16: 22-24.

Holland, M. P., D. K. Skelly, M. Kaskgarian, S. R. Bolden, L. M Harrison, and M. Cappello. 2007. Echinostome infection in green frogs (Rana clamitans) is stage and age dependent. Journal of Zoology 271: 455-462.

HuelsenbeCK, J. P., AND F. Ronquist. 2001. MRBAYES: Bayesian inference of phylogenetic trees. Bioinformatics 17: 754-755.

INGLES, L. G. 1935. Notes on the development of a heterophyid trematode Transactions of the American Microscopial Society 54: 19-21.

Johnson, P. T. J., R. B. Hartson, D. J. Larson, and D. R. Sutherland. 2008. Diversity and disease: Community structure drives parasite transmission and host fitness. Ecology Letters 11: 1017-1026.

-, K. B. Lunde, E. G. Ritchie, and A. E. Launer. 1999. The effect of trematode infection on amphibian limb development and survivorship. Science 284: 802-804.

, E. M. Thurman, E. G. Ritchie, S. N. Wray, D. R. Sutherland, J. M. Kapfer, T. J. Frest, J. Bowerman, and A. R. Blaustein. 2002. Parasite (Ribeiroia ondatrae) infection linked to amphibian malformations in the western United States. Ecological Monographs 72: 151-168

Joy, J. E., And J. L. Pennington. 1998. Ecology of Megalodiscus temperatus (Digenea: Paramphistomatidae) in red-spotted newts, Notophthalmus v. viridescens, from West Virginia. Journal of the Helminthological Society of Washington 65: 205-211.

Kaplan, A. T., S. Rebhal, K. D. Lafferty, and A. M. Kuris. 2009. Small estuarine fishes feed on large trematode cercariae: Lab and field investigations. Journal of Parasitology 95: 477-480.

Koprivnikar, J., R. L. BAKer, AND M. R. Forbes. 2006. Environmental factors influencing trematode prevalence in grey tree frog (Hyla versicolor) tadpoles in southern Ontario. Journal of Parasitology 92: 997-1001.

Kuris, A. M., R. F. Hechinger, J. C. Shaw, K. L. Whitney, L. AguirreMacedo, C. A. Boch, A. P. Dobson, E. J. Dunham, B. L. Fredensborg, T. C. Huspeni, et Al. 2008. Ecosystem energetic implications of parasite and free-living biomass in three estuaries. Nature 454: 515-518.

Lafferty, K. D., S. Allesina, M. Arim, C. J. Briggs, G. De Leo, A. P. Dobson, J. A. Dunne, P. T. J. Johnson, A. M. Kuris, D. J. Marcogliese, et AL. 2008. Parasites in food webs: The ultimate missing links. Ecology Letters 11: 533-546.

LANG, B. Z. 1968. Note on ecology of Goniobasis proxima in North Carolina. Nautilus 82: 3-5.

, And L. N. Gleason. 1967. Life cycle of Metagonimoides oregonensis Price, 1931 (Trematoda: Heterophyidae) in North Carolina. Journal of Parasitology 53: 93.

- - AND B. R. ForD. 1968. Morphological differences between population samples of Metagonimoides oregonensis Price, 1931 (Trematoda: Heterophyidae) from Oregon and North Carolina. Journal of the Elisha Mitchell Scientific Society 84: 281-284.

Larkin, M. A., G. Blackshields, N. P. Brown, R. Chenna, P. A McGettigan, H. McWilliam, F. Valentin, I. M. Wallace, A WiLm, R. Lopez, et AL. 2007. Clustal W and clustal X version 2.0. Bioinformatics 23: 2947-2948.

Locke, S. A., J. D. McLaughlin, A. R. Lapierre, P. T. J. Johnson, and D. J. Marcogliese. 2011. Linking larvae and adults of Apharyngostrigea cornu, Hysteromorpha triloba, and Alaria mustelae (Diplostomoidea: Digenea) using molecular data. Journal of Parasitology 97: 846-851

- - AND D. J. Marcogliese. 2010. DNA barcodes show cryptic diversity and a potential physiological basis for host specificity among Diplostomoidea (Platyhelminhtes: Digenea) parasitizing freshwater fishes in the St. Lawrence River, Canada. Molecular Ecology 2010: 2813-2827.

Los Alamos National Laboratory. 2010. FindModel. Available at http://www.hiv.lanl.gov/content/sequence/findmodel/findmodel.html. Accessed 2 April 2012.

McAlpine, D. F., And M. D. B. Burt. 1998. Helminths of bullfrogs, Rana catesbeiana, green frogs, $R$. clamitans, and leopard frogs, $R$. pipiens in New Brunswick. The Canadian Field-Naturalist 112: 50-68. 
Milanovich, J. R. 2010. Modeling the current and future roles of stream salamanders in headwater streams. Ph.D. Dissertation. D. B. Warnell School of Forestry and Natural Resources, University of Georgia, Athens, Georgia, $156 \mathrm{p}$

NaJARIAN, H. H. 1955. Trematodes parasitic in the Salientia in the vicinity of Ann Arbor, Michigan. American Midland Naturalist 53: 195-197.

Olson, P. D., T. H. Cribb, V. V. Tkach, R. A. Bray, and D. T. J. LitTlewood. 2003. Phylogeny and classification of the Digenea (Platyhelminthes: Trematoda). International Journal for Parasitiology 33: 733-755.

Peterman, W. E., J. A. Crawford, and R. D. Semlitsch. 2008. Productivity and significance of headwater streams: Population structure and biomass of the black-bellied salamander (Desmognathus quadramaculatus). Freshwater Biology 53: 347-357.

Petranka, J. W. 1998. Salamanders of the United States and Canada. Smithsonian Institution Press, Washington, D.C., 576 p.

PRICE, E. W. 1931. Metagonimoides oregonensis, a new trematode from a raccoon. Journal of the Washington Academy of Sciences 21: 405-407.

Prudhoe, S., and R. A. Bray. 1982. Platyhelminth parasites of the amphibia. Oxford University Press, London, U.K., 217 p.

Schaffer, G. D., W. R. Davidson, V. F. Nettles, and E. A. Rollor, III. 1961. Helminth parasites of translocated raccoons (Procyon lotor) in the southeastern United States. Journal of Wildlife Diseases 17: 217-227.

Schell, S. C. 1985. Trematodes of North America. University of Idaho Press, Moscow, Idaho, $263 \mathrm{p}$.

Schotthoefer, A. M., R. A. Cole, and V. R. Beasley. 2003. Relationship of tadpole stage to location of echinostome cercariae encystment and the consequences for tadpole survival. Journal of Parasitology 89: 475-482.

, J. R. Rohr, R. A. Cole, A. V. Koehler, C. M. Johnson, L. B. Johnson, And V. R. Beasley. 2011. Effects of wetland vs. landscape variables on parasite communities of Rana pipiens: Links to anthropogenic factors. Ecological Applications 21: 1257-1271.

Senger, C. M., and R. W. Macy. 1952. Helminths of northwest mammals. Part III. The description of Euryhelmis pacificus n. sp., and notes on its life cycle. Journal of Parasitology 38: 481-486.

Smyth, J. D., And M. M. Sмyth. 1980. Frogs as host-parasite systems. MacMillan Press, Hong Kong, China. 112 p.

Sutherland, D. 2005. Parasites of North American frogs. In Amphibian declines: The conservation status of United States species, M. J. Lannoo (ed). University of California Press, Berkeley, California, p. 109-123.

Szuroczki, D., And J. M. L. Richardson. 2009. The role of trematode parasites in larval anuran communities: An aquatic ecologist's guide to the major players. Oecologia 161: 371-385.

Tamura, K., D. Peterson, N. Peterson, G. Stecher, M. Nei, and S. KUMAR. 2011. MEGA5: Molecular evolutionary genetics analysis using maximum likelihood, evolutionary distance, and maximum parsimony methods. Molecular Biology and Evolution. 28: 27312739.

Zelmer, D. A., ANd G. W. Esch. 2000. Relationship between structure and stability of a Halipegus occidualis component population in green frogs: A test of selective treatment. Journal of Parasitology 86: 233240 . 